\title{
Exploring the Concept of Containment, Childhood Development and Silence in Alex Michaelides's Novel The Silent Patient: A Psychoanalytic Critique
}

\author{
Mohammad Afzal Hossain \\ Lecturer, Department of English, Mawlana Bhashani Science and Technology University, Bangladesh
}

\begin{abstract}
This paper focuses to appropriate and apply the concepts of "container- contained" and "holding and holding environment" theorized respectively by Wilfred Bion and Donald Winnicott, across the nature of Alicia's relationships with her father and husband to understand the resultant silence after her husband's murder in the novel The Silent Patient. The objective of this paper is to explore and investigate how the nature of child Alicia's relationship with her father impacted her childhood psychic development and how this leads to her husband's murder from psychoanalytic perspectives of Bion and Winnicott. The childhood development of Alicia has been traced and explored deploying various concepts developed by Freud, Bion, Winnicott and Lacan using in-depth qualitative methods like content analysis and textual analysis. The paper finds that, the nature of Alicia's relationship with her husband and the murder has interconnectedness with the nature of relationship Alicia had with her father. Alicia didn't get a containing and holding environment during childhood. The importance of this paper lies in its scope and spectrum of revisiting the reinforced focus on having a contained and safe childhood development.
\end{abstract}

Keywords: Container-Contained, Childhood Development, Silence, Psychoanalysis, Holding Environment.

\section{INTRODUCTION}

$\mathrm{T}$ The way one's childhood is developed plays a very vital role in forming the personality and identity of one during the subsequent stages of life. This view of identity and predicament development has been widely explored and applied in a varied range of literature. Significance of childhood experiences and memory in forming the adult identity is thebasis for conceptualizing the personality development and disorder in the psychoanalytic realm of Freud. Freud is not the only one who has drawn extensively from childhood memories and experiences to analyze and understand some mental and psychic process in adults, Lacan(2013) has his own tripartite (Imaginary, Symbolic and Real) model of conceptualizing the child identity development with an added emphasis on the language when realm of signification is initiated in Symbolic order. Roos (2001) states Lacan's picture of the symbolic-real-imaginary orders are deeply rooted in Freudian notions of the oedipal phase, infantile sexuality, and the project of uncovering unconscious processes through language and associations.

There are obviously other theories and conceptualizations to understand the psychic and mental processes in adults with conditions like psychosis, neurosis, anxiety disorder, ADHD, identity crisis, fear of death, fear of abandonment, fear of insignificance, fear of being not loved etc. There are many more other psychiatric conditions which have been taken into account in various experimentation and theorization to figure out the causes behind these conditions keeping the lens pointed toward childhood and the memories of that time.

From generic point of view the novel The Silent Patient by Alex Michaelides, published in 2019, can be categorized as a psychological thriller with two plots intertwined with each other. As the academy award winning director of Shakespeare in Love (1998) John Madden puts forward -"psychological thrillers focus on story, character development, choice, and moral conflict; fear and anxiety drive the psychological tension in unpredictable ways", the story, character development and tension unfolds in this novel through one plot narrating the story from first person point of view of Theo Faber, a forensic psychoanalyst, to find out the reasons behind silence of Alicia after the murder of her husband. This plot also betrays who Theo Faber is, what was his childhood like, his parents, his family and his wife Kathy. Theo can be assumed as alter male persona of Alicia when we take a deeper look into his childhood, his relationship with his father and his love and family life with Kathy. Both Alicia and Theo are betrayed by their loved ones. Alicia is betrayed by her husband Gabriel Berenson; and Theo is betrayed by his wife Kathy. Gabriel had an affair with Kathy.

The second plot has been fleshed with the story of Alicia writing her diary. The novel starts with an epilogue of Alicia writing her diary. Through this diary motif, the readers can have an intimate glimpse of the information, facts, truths and history about Alicia. The diary motif has also functioned as an element of suspense, element of revelation and also an element working as the machinery of "wiling suspension of disbelief (Coleridge, 1907). The readers tend to assume whatever Alicia has written in the diary as true, willingly negating the possibility of lies and distortions Alicia might use, considering her state of mind. We can have a glimpse about her state of mind at the very beginning of the novel when she writes in her diary "I have been feeling depressed lately" (Michaelides, p. 7), and before this she appears to be confused about what this diary writing practice should be called, a diary or journal and later she decides not to name it 
all. Assumptions about her mental state can be formedwhen she forces herself in auto-suggestive way to write only the "positive, happy, normal thoughts" only in the diary (Michaelides, p. 8). She is struggling with negative thoughts and she is repressing and hiding something that she cannot even write down in her diary. Here in the very beginning we see the foreshadowing of the repressed and suppressed world of desire, dreams, trauma, and anxiety of Alicia. The reader is gradually exposed to the distant past and memories back in the childhood of Alicia,these memories deposited in the mind of the 33 years old genius painter is a repository of suppressed desires and trauma that triggers her to murder her husband.

Within the novel itself, Theo Faber, a forensic psychotherapist has engaged himself in unearthing the reasons behind the predicament of Alicia by gathering information from her past; and the readers in the course of reading the novel get to know why Alicia killed Gabriel with so intense a murderous rage. Despite knowing the whole picture of the past, it is important to delve into this causal relationship of the events in Alicia's life from a perspective, outside of the text, outside of the point of view of the novel's characters, outside the perspective of Theo.

Theo Faber tries to figure out why Alicia is the way she is-

"A simple analogy might be helpful: a leading psychiatrist in the field of sexual abuse once told me she had, in thirty years of extensive works with pedophiles, never met one who hadn't himself been abused as a child. This doesn't mean that all abused children go on to become abusers, but it is impossible for someone who was not abused to become an abuser. No one is born evil. As Winnicott put it "a baby cannot hate the mother, without the mother first hating the baby". As babies we are innocent sponges, blank slates, with only the most basic needs present: to eat, to shit, love and be loved. But something goes wrong, depending on the circumstances into which we are born and the house we grow up. A tormented abused child can never take revenge in reality, as she is powerless and defenseless, she can- and must-harbor vengeful fantasies in her imagination. Rage like fear is reactive. Something has happened to Alicia probably early in her childhood, to provoke the murderous impulses that emerged all those years later. Whatever the provocation, not everyone in this world would have picked up the gun and fired it pointblank into Gabriel's face, most people could not, would not do this.. That Alicia did so, points to something disordered in her internal world." (Michaelides, p. 123-124).

\section{LITERATURE REVIEW}

There is no substantial literature found on the novel Silent Patient except for some scattered reviews and commentary, but almost no scholarly materials. The novel was published in 2019 which was at the top of the list of New York Times bestseller books and it is the debut novel of Alex Michaelides. This popular psychological thriller novel was taken into consideration to write this paper, as the novel focuseson the importance of a balanced and healthy childhood which is required to develop a healthy adult. Keeping aside the popular charm for suspense and thrill, the novel can be treated as an exploration on the spectrum of childhood development from a psychological perspective, which can easily be assumed very relevant for $21^{\text {st }}$ century when there are a lot of personal, familial, social, communal, national and international issues at play that might hamper healthy childhood development. It cannot be denied that, there are also tremendous developments in the field of child psychology, social psychology, family psychology, relationship management that aim to ensure a healthy development of a child, of a family. The novel Silent Patient might work as a reminder- in the form of a thriller- of how important childhood is, why the mental and psychological factors of a child should be treated with care, why a healthy family environment, a holding and containing environment is required.

Bianchini, Dallanegra \& O'Flaherty (2011) have explained the importance of having a holding environment, of having someone, to whom one can turn to in times of emotional needs for support and help. "When it transpires that the capacity of a person's mind for dealing with mental suffering is inadequate, there is the urge to seek out another mind that can help to face the pain in an attempt to overcome the individual's suffering and in the hope of change." (Bianchini, Dallanegra \& O'Flaherty, 2011).

In this paper the term containment and holding have been used interchangeably though there are some major differences between the conceptualizations of Bion and Winnicott, regarding the developmental stages of a child and its relationship with its mother or caregiver. Parry (2010) has identified some major comparative and contrastive differences between the developmental theory and model of mind of Bion and Winnicott. But both have agreed on the importance of having a safe environment for the balanced and healthy development of a child. Here in this paper both the terms "containment" and "holding" has been used to refer to a safe developmental environment and the term "container" to refer to a caring, trustworthy mother or caregiver.

Winnicott (1947) explains in his paper when a child is deprived of basic emotional and physical needs in the past, the child begins to develop a mixed feeling of hope and fear in the form of defense in the new adopting or holding and containing environment. The child perpetually remains in fear of disappointment from the container. At this point, the relationship of Alicia and Gabriel can be brought back into consideration. Alicia with a dissatisfactory past upbringing, marries Gabriel and finds a containing environment but she is always in a state of fear that she might lose Gabriel, as evident from her diary entries.

Winnicott (1947) argues the health of the grown-up person depends on the person's childhood, but the foundation of the health of the human being is laid by you in the baby's first weeks and months. 
Bion (1970) did not use the term containment or containing in any of his writing. He has coined and used the "containercontained" model to describe the baby-mother relationship. And later the nature of relationship has been extended to cover not only individual relational levels but also group relationships.

Bion and Winnicott hold a very significant importancein the arena of child psychology and child development, but in a very few instances their ideas have been applied to analyze a literary texts like novel, poetry, short story, play etc. The psychoanalytic theorizations and concepts of Freud, Lacanand Carl Jung have secured an essential place in both literary and cultural criticism and theories but the works of Bion and Winnicott have not been adopted and adapted to understand a literary text from a psychoanalytic perspective. Most of the books on literary and cultural theories start their psychoanalytic critical discussion with Freud and ending with Lacan until recently Carl Jung has been added to the discussion (Nayar, 2009).Alfred Adler has also been brought to the frontline to analyze a literary texts. But very few works have been produced that have applied the psychoanalytic conceptions of Bion and Winnicott in analyzing and theorizing a literary text.

Rudnytsky(1991) expressed his dissatisfaction and pointed inadequacy regarding Lacanian psychoanalysis and feels a need for an alternative. He thinks of Winnicott as the possible alternative. In his words-"although I encountered the work of Lacan in graduate school, his postmodern inflection of psychoanalysis left me dissatisfied and I sought a figure through whom I could articulate an alternative vision of its possibilities. The alternative I have found belatedly in Winnicott."

Bion and Winnicott can provide- if not an alternative to Freud andLacan in the textual analysis of a text from psychoanalytic point of view, but a fuller and deeper understanding and insights on the human mind including childhood development and other stages that humans go through.

The literature discussed above on the concept of containment and holding, show how the intellectually rigorous idea of container-contained have mostly been used for clinical psychiatric purpose, but these ideas have been used very little to analyze a literary text like a novel to understand the nature of human relationships, in this paper, relationship of Alicia with her father and husband and even others not excluding Theo Faber have been analyzed.

This paper intends to explore and analyze the novel The Silent Patient from a psychoanalytic theoretical perspective applying the tools developed by Bion and Winnicott. The concept of "container-contained" and holding environment has been considered as tools to delve into the psyche of Alicia to understand the link between childhood development and adult predicament.

Freud is the most popular one to be used in analyzing a literary text from psychoanalytic theoretical stance. This novel can definitely be read using the significant ideas developed by Freud. Freud's (1977) conceptualization on Core issues: fear of intimacy, fear of abandonment, fear of betrayal, low selfesteem, insecure or unstable sense of self, oedipal fixationcan be one of them. From the perspective of Lacanian psychoanalysis the novel has the possibility to be read within the concepts such as "Other", "discourse" of the Other, as Lacan(1968) states our deepest thoughts are formed by the language of the other and we understand the world through the language and discourse of the other. For Alicia her father and her husband have functioned as the other, and they are the ones in terms of whom she has developed her worldview, formed her psychic universe. Once language and discourse have fallen apart her inner world fell apart too.

In this paper psychoanalytic concepts of both Lacan and Freud have been applied where deemed necessary but focus has been dispatched mostly on applying the less explored and less applied ideas, at least in English Literature, developed by Bion and Winnioctt to understand the novel.

\section{METHODOLOGY}

Content analysis and textual analysis methods have primarily been used to critically analyze the textual resources and contents. The paper has also used some cultural studies research methods tools like taking an eclectic approach and qualitative in-depth analysis of written discourse. Various relevant theoretical and conceptual frameworks have been deployed to posit the discussion and analysis in a bigger picture. Mostly, psychoanalytic theory of Freud, Lacan, Bion, Winnicott has been used to understand and analyze the texts and other literatures. Besides various psychoanalytic theories, Linguistic concepts and theories like psycholinguistics, child language acquisition, language loss and deprivation etc.have also been used where deemed relevant within the scope of the paper.

\section{RESULTS AND DISCUSSION}

The role of caregiver, in the context of this paper -the role of container or holder in forming a balanced and healthy psychic world in infants has been widely discussed, explored and investigated in different disciplines ranging across linguistics, psychiatry, psychoanalysis etc. Language, viewed as behavior to be acquired and learned can be best mastered when caregiver gives sufficient inputs either in the form of baby talks, nonverbal, sounds etc. In developmental psycholinguistics or child language acquisition process, caregiver speech, both verbal and nonverbal, even a small gesture play a vital role in facilitating the language acquisition of a child(Steinberg, 1993).

There are many natural and also experimental incidents where human child have been deprived of language, and they have been used to find out the critical age for language learning. Among many of these incidents there are stories of feral childlike Genie and others where in one instance a child is confined in a room with her mute mother and the child did not develop any understandable language (Steinberg, 1993). There 
are evidences that show if the caregiver communicates less with the baby the baby might develop speech disorder of any sort, starting with stammering. This is just one example of language acquisition but the issue of language loss is even morecomplex and complicated than the language acquisition itself.

Psycholinguistics along with Neurolinguistics has given deeper understanding on the issue of language deprivation and language loss. Old age and many other mental, psychological and physical factors contribute to the process of language disintegration and language dissolution(Steinberg, 1993). There are evidences that psychological factors like trauma, PTSD, shock, betrayal, realization of one's assumed worthlessness etc. can lead to the instantaneous loss of language and hence can induce silence in a person. The imprint of some particular life experiences on the mind can develop in the person a sort of apathy and indifference for using any verbal or nonverbal language, and will make it very difficult to figure out what is going on in the mind of that person. The case of Alicia Berenson can be treated as an example here. Only "talking therapy" as postulated by Freud might fail in this regard. But Freud has indicated another way of communicating with a silent patient like Alicia. Freud (1977) argues "if the lips are silent, he chatters with his fingertips". Freud thinks nonverbal cues or signs of the patient can be observed to make a bridging countertransference between the therapist and the patient. Theo Faber tries to communicate with Alicia using nonverbal ways, but with no significant result.

“Therapy is not just about talking. It's about providing a safe space-a containing environment. Most communication is nonverbal" Indira said to Theo (Michaelides, p. 70).

These are some of the examples to elucidate the importance of caregiver, in this context, importance of container and holding environment in shaping the psychic world of an infant including the linguistic behavior. Silence, whether clinical, psychological or social, can arguably be placed in the whole spectrum of human linguistic behavior.

Likely in other disciplines, the importance of caregiver in forming not only the linguistic behavior but also a person's behavior in total, the whole personality, the identity itself has been arguably accepted. If the experience and memory of a child with its caregiver up to a certain age is balanced and healthy the child becomes a healthy adult in later life. If otherwise, the child might appear to be a healthy adult in later stages of life but will carry with him or her a repository of suppressed and repressed desires, dreams, anxiety, fear, and hatred, vengefulness in the unconscious and subconscious part of mind. He or she even stays unaware of this repository until and unless they get triggered and come out in the uglier ways.

The case of Alicia murdering her husband is the result of the exposure of the repressed and suppressed childhood experiences in her family. Her mother died in a car crash and her father wished Alicia died instead of her mother. Alicia overheard this when she was a child and developed a sense of being unloved, unwanted for, insignificant, betrayed and killed. Alicia was a victim of psychic infanticide by her father. Her father did not kill her biologically but psychically. This impression of her murder, remained with her throughout her life into adulthood. Before meeting Gabriel, Alicia used to lead a life of 'druggy partiers' and had no certainty in her life. After she meets Gabriel, shethinks her life falls into place. She is never the same as before. Alicia thought of Gabriel as Jesus, who saved her from the psychic darkness. Aliciafound a holding environment, a container which she has long been denied after the death of her mother and also the death of her father's love for her since the day of her psychic killing. Now after Gabriel and Alicia get married she feels contained, saved and secured.

From the point of view of "subject position" outlined in the lecture on "Technologies of the Self" by Nilson (1998)as ideated by Foucault (1988), we can also note how the subject position gets changed, as a process of psychic order management. The father of Alicia was certainly in grief and shock, losing his wife in the car crash. He out of despair and grief wished her wife be saved and his daughter Alicia be dead instead. Alicia was in the car during the crash and she survived. Alicia was also feeling what is called survivors guilt. But she could not process how her father killed her in place of her mother, as Alicia thought her father loves her and cares for her. Eventually she finds out otherwise and feels betrayed.

The same pattern of switching the subject position can be observed when Alicia meets Gabriel, a replacement for her father figure who would love her this time, protect her and will not betray her. All of her life she has craved for a father figure unlike her own father who considered herself as a sacrilege. Her surrogate father figure Gabriel becomes her container and she becomes contained in it within a holding environment. In her subconscious mind she was always carrying very silently a desire to kill her father, to avenge her own psychic infanticide, to take revenge on her father for the betrayal. It has always been there in her psychic world lurking to come out to materialize its desire of killing the one who betrayed. This desire comes out in an uglier way once Alicia finds out the betrayal, disloyalty of Gabriel. It is not the affair Gabriel was having with the wife of Theo that made her murder Gabriel so grotesquely and made her mute and silent eventually. It was the same ritualistic way of sacrificing Alicia when Theo Faber asked Gabriel to choose who wouldlive and who would die. Gabriel did not want to die. He chose Alicia to die in place of him. This draws Alicia to a series of realization and feelings. Again she has been betrayed as she thought Gabriel loves her and can even die for her. But she finds out otherwise. After Theo is gone Alicia takes the pistol and shoots Gabriel six times. She writes- it is not Gabriel who is killed but it is her who has been murdered, not physically though but psychically.

But she could have spared Gabriel. They could have gone on after this event. But the rage, the desire of taking revenge on 
her father came out and Alicia realized the same feelings of betrayal, she felt unloved andunwanted and she shot not one time but six times on the face of Gabriel. The suppressed and repressed desire from herchildhood comes out in an uglier way.

After this incident she stays silent and mute like Alcestis in the play by Euripides, the Greek mythical story retold. Alicia is the modern Alcestis. Alicia is the embodiment of unresolved childhood anxiety and trauma. Alicia is the expression of the state where language becomes insufficient to express feelings or thought. Alcestis in the mythical story sacrificed her life in the place of her husband Admetus. And when she comes out of death she never spoke. The question was "why didn't she speak" (Hughes\&Euripides, 1999). The answer is Silence. The answer lies in the concept of container and containment. Speech and language operates in containment, when a child feels safe and contained. It can learn the language. It can communicate and speak. But when the containment is breached and compromised the speech is lost, the language is lost.

The silence of Alicia is not induced out of any mental disorder rather out of a realization of double recurrence of the same cycle of betrayal, and not being loved. It will be relevant to refer to what Paulo Coelho asserts about the happening of the same event again and again. "Everything that happens once can never happen again. But everything that happens twice will surely happen a third time" (Coelho, 2017). Alicia has experienced an identical pattern of betrayal and killing, at least twice within her reaching 33 years in life. She has realized Gabriel had killed her the same way her father did when Gabriel chose Alicia to die instead of him. "I don't want to die, he said" when Theo asked Gabriel to choose between Gabriel himself and Alicia to die(Michaelides, p. 280). Gabriel did not only betray Alicia through his affair with Kathy, wife of Theo, he has also sentenced her to death like her father did. Gabriel did even more than Alicia's father did, he did not only sentence her to death corporally but also psychically. Alicia's father wished her to die instead of her mother who died in a car crash where Alicia survived.

The nature and dimension of betrayal and psychic homicide from her father and her husband may be different in some aspects but the implications and essence are identical. In both the cases, Alicia's containment has been shattered and breached. The containers, father and husband, failed to contain her as they are supposed to do. The holding environment around her collapsed so did her inner world. This knowledge and realization, for a genius painter like her, renders Alicia silent knowing that she is beyond love beyond cared for, beyond redeemed and there is nothing left to struggle, to say, rather to stay silent. She introspected and retrospected:

"I saw it now. I would never be safe. Never be loved. All my hopes dashed -all my dreams shattered-leaving nothing, nothing, my father was right-I didn't deserve to live. I wasnothing. That's what Gabriel did to me. That's the truth. I didn't kill Gabriel. He killed me. All I did was to pull the trigger"(Michaelides, p. 282).

There are many instances where individuals have lost their speech not due to any damage in the frontal lobe or in the Language Acquisition Device or any physical part of the brain or body(Chomsky, 1965). But they have lost their speech due to some psychological events like betrayal, breach of belief and trust, sudden shock etc.

The case of Alicia is of latter kind. She has developed her speechlessness or silence not due to any damage in the neurons but on the deeper psyche. She becomes silent not because she could not talk but because she will not talk or it can be said she lost the interest to communicate verbally. She has painted Alcestis, a painting that she worked on when she was house arrested after the murder of Gabriel. It shows she after all wanted to communicate, wanted to be redeemed and saved from her psychic darkness. Her only way of communication was to find out an allusion that would best describe her predicament and mental conditions. She chooses to paint a self-portrait and name the painting Alcestis, to give an outlet of her inner world, drawing a parallelism between "Alcestis" of Greek mythological story retold by Euripides. Alcestis was also not contained and held with trust and love by her husband Admetus. The concept of trust is very importantly associated with the idea of containment. The container must be trustworthy for the contained otherwise the communication fails, the development fails and silence is staged.

Theo's therapist Ruth told him about the importance of honesty in love and said that, "love that does not include honesty does not deserve to be called love" which can be projected into the nature of relationship between Alicia and Gabriel (Michaelides, p.97).

The term containment is related "to describe a mother's ability to manage her baby's pain. Babyhood is not a time of bliss, it's one of terror. As babies we trapped in a strange, alien world, unable to see properly, constantly surprised at our own bodies, alarmed by hunger and wind and bowel movements, overwhelmed by our feeling. We are quite literally under attack. We need our mother to soothe our distress and make sense of our experiences. But our ability to contain ourselves directly depends on our mother's ability to contain us. Someone who has never learned to contain himself is plagued by anxious feelings for the rest of his life, feelings that Bion aptly titled "nameless dread". Such person endlessly seeks this unquenchable containment from external sources" (Michaelides, p. 80).

This is one of the internal monologues of Theo Faber to understand the predicament of Alicia and also of himself. Theo's childhood was also not a pleasant experience for him. He was never contained by his parents and has developed the "nameless dread" which through "external source" marijuana he tries to appease.

For Alicia, Gabriel was marijuana, that external source, or in the term of Lacan (1968), "discourse" of the "Other" that not 
only gave her a sense of self, but also a refuge from nameless dread. Alicia writes in her diary- "he saved me like Jesus" as "I lost myself." "Gabriel is my whole world-has been since the day we met. I will love him no matter what he does, or what happens, no matter how much he upsets me......I will take him just as he is. Until death do us apart." (Michaelides, p. $60)$.

Bionian(1962) object relations theory can further deepen our understanding about the nature of relationship Alicia had with both her father and husband. The theory with its focus on the relationship between mother and infant and the process of development of the later, also designates how the personality and identity is gradually formed in relation to the external people as well as internal images. Alicia has grown up keeping in mind the image of the experience from the psychic infanticide by her father and later she has developed a relationship with Gabriel, who has worked as "Other" to contain her.

Here the idea of commensal, symbiotic and parasitic type of relationship categorized by Bion (1970) can cast even further light in understanding the nature of relationship Alicia and Gabriel had or at least how Alicia views the relationship. Bion formulated the essential relationship between thinking and communicating in terms of the "container-contained" relationship. He described three types of communication, occurring on different levels of development: commensal, symbiotic, and parasitic.

To describe these three relational levels in simple terms would be-commensal relation is where one gets benefitted while another is unaffected, in symbiotic relationship both gets benefitted and in parasitic relationship one gets benefitted and the host gets harmed. Bion has emphasized on the symbiotic type of communication and relationship development between the container and contained. But the relationship of Alicia and Gabriel might seem at first very symbiotic, but eventually we realize that, though Gabriel the host is not harmed not until he is shot dead, Alicia had developed a parasitic relationship with Gabriel from whom she draws the energy and meaning of her life as she feels contained with Gabriel. The relationship of container and contained between Alicia and Gabriel is best described as parasitic not symbiotic let alone commensal.

The childhood experiences of Alicia did not allow her, at least subconsciously, to develop a healthy symbiotic relationship with the container, with her husband Gabriel.

\section{CONCLUSION}

After this critical and analytical overview of the whole landscape of the interpersonal and intrapersonal relationship in the novel frompsychoanalytic point of view, it can be assumed that childhood definitely plays an important role in developing the psyche in totality in adults. The causes of the effects developed among adults can be traced back in the childhood. The case of Alicia does not only shed light on the interconnectivity of this causal relationship but also on the importance of having a contained childhood experience. Otherwise communication in the self of the language falls apart and consequently silence takes over.

\section{REFERENCES}

[1] Bianchini, B., Dallanegra, L., \& O'Flaherty, R. (2011). Reflections on the container-contained model in couple psychoanalytic psychotherapy. Couple and family Psychoanalysis, 1(1), 69-80.

[2] Bion, W. (1962). Learning from experience, London: Karnac Books.

[3] Bion, W. (1970). "Container and contained". In attention and interpretation, London: Tavistock.

[4] Chomsky, N. (1965). Aspects of the theory of syntax. MIT Press.

[1] Coelho, P. (2017). Alchemist, the (75th ed.). HarperCollins. London.

[2] Coleridge, S. T.\&Shawcross, J. (1907). Biographialiteraria. Oxford: Clarendon Press.

[3] Foucault, M. (2019). Ethics: subjectivity and truth: essential works of Michel Foucault 1954-1984. Penguin UK.

[4] Freud, S. (1977). Introductory lectures on psychoanalysis. WW Norton \& Company.

[5] Hughes, T. \& Euripides, (1999). Euripides' Alcestis. New York: Farrar, Straus and Giroux.

[6] Lacan, J. (1968). The language of the self: The function of language in psychoanalysis. JHU Press.

[7] Lacan, J. (2013). The ethics of psychoanalysis 1959-1960: The seminar of Jacques Lacan. Routledge.

[8] Loos, A. (2001). Symbolic, real, imaginary. Csmt.uchicago.edu. https://csmt.uchicago.edu/glossary2004/symbolicrealimaginary.ht m\#: :text=The\%20mirror\%20stage\%20thus\%20represents,ideolog y\%20\%E2\%80\%93\%20through\%20the\%20various\%20Ideologica 1.

[9] Michaelides, A.(2019). The silent patient. New York: Celadon.

[10] Nayar, P. K. (2009). Contemporary literary and cultural theory: From structuralism to ecocriticism. Pearson Education India.

[11] Nilson, H. (1998). Technologies of the Self. In: Michel Foucault and the Games of Truth. Palgrave Macmillan, London.

[12] Parry, R. (2010). A critical examination of Bion's concept of containment and Winnicott's concept of holding, and their psychotherapeutic implications (Doctoral dissertation).

[13] Psychological thriller - Wikipedia. En.wikipedia.org. (2021). https://en.wikipedia.org/wiki/Psychological_thriller.

[14] Rudnytsky, P. L. (2013). The psychoanalytic vocation: Rank, Winnicott, and the legacy of Freud. Routledge.

[15] Steinberg, D. D. (1993). An Introduction to Psycholinguistics. Routledge.

[16] Winnicott, D. W. (1947). Hate in the countertransference. London: Tavistock.

[17] Winnicott, D. W. (2013). The child and the family: First relationships (Vol. 6). Routledge. 